\title{
EFFECTS OF DAMS IN RIVER NETWORKS ON FISH ASSEMBLAGES IN NON-IMPOUNDMENT SECTIONS OF RIVERS IN MICHIGAN AND WISCONSIN, USA ${ }^{\dagger}$
}

\author{
LIZHU WANG,${ }^{\mathrm{a} *}$ DANA INFANTE, ${ }^{\mathrm{b}}$ JOHN LYONS, $^{\mathrm{c}} \mathrm{JANA}^{\mathrm{S}}$ STEWART ${ }^{\mathrm{d}}$ and ARTHUR COOPER ${ }^{\mathrm{a}, \mathrm{b}}$ \\ ${ }^{a}$ Institute for Fisheries Research, Michigan Department of Natural Resources, University of Michigan, 1109 N. University, Ann Arbor, MI 48109, USA \\ ${ }^{\mathrm{b}}$ Department of Fisheries and Wildlife, Michigan State University, 13 Natural Resources, East Lansing, MI 48824, USA \\ ${ }^{c}$ Wisconsin Department of Natural Resources, 2801 Progress Road, Madison, WI 53716, USA \\ ${ }^{\mathrm{d}}$ U.S. Geological Survey, 8505 Research Way, Middleton, WI 53562, USA
}

\begin{abstract}
Regional assessment of cumulative impacts of dams on riverine fish assemblages provides resource managers essential information for dam operation, potential dam removal, river health assessment and overall ecosystem management. Such an assessment is challenging because characteristics of fish assemblages are not only affected by dams, but also influenced by natural variation and human-induced modification (in addition to dams) in thermal and flow regimes, physicochemical habitats and biological assemblages. This study evaluated the impacts of dams on river fish assemblages in the non-impoundment sections of rivers in the states of Michigan and Wisconsin using multiple fish assemblage indicators and multiple approaches to distinguish the influences of dams from those of other natural and human-induced factors. We found that environmental factors that influence fish assemblages in addition to dams should be incorporated when evaluating regional effects of dams on fish assemblages. Without considering such co-influential factors, the evaluation is inadequate and potentially misleading. The role of dams alone in determining fish assemblages at a regional spatial scale is relatively small (explained less than $20 \%$ of variance) compared with the other environmental factors, such as river size, flow and thermal regimes and land uses jointly. However, our results do demonstrate that downstream and upstream dams can substantially modify fish assemblages in the non-impoundment sections of rivers. After excluding river size and land-use influences, our results clearly demonstrate that dams have significant impacts on fish biotic-integrity and habitat-and-social-preference indicators. The influences of the upstream dams, downstream dams, distance to dams, and dam density differ among the fish indicators, which have different implications for maintaining river biotic integrity, protecting biodiversity and managing fisheries. Copyright (C) 2010 John Wiley \& Sons, Ltd.
\end{abstract}

KEY WORDS: impoundment; fish diversity; fish integrity; river connectivity; cumulative effect

Received 14 August 2009; Revised 25 November 2009; Accepted 4 December 2009

\section{INTRODUCTION}

River systems in North America and many other parts of the world are fragmented by multiple dams. A recent compilation by the US Army Corps of Engineers lists approximately 35000 dams in the United States alone that are $25 \mathrm{ft}$ high and impound an area of at least 15 acre-feet (USACE, 2009). Globally, at least 40000 large dams exist; this number includes structures at least $15 \mathrm{~m}$ high or taller (Helfman, 2007; International Rivers, 2009), with as many as 1000000 smaller dams world-wide (Allan and Castillo, 2007). Dams regulate flows, generate hydropower and provide water for industry, irrigation and human consumption. However, dams have been recognized as one of the primary means by which humans alter fluvial ecosystems (Rosenberg et al., 1997; Greathouse et al., 2006). Dams convert river sections from

\footnotetext{
*Correspondence to: Lizhu Wang, Institute for Fisheries Research, Michigan Department of Natural Resources and University of Michigan, 1109 N. University, Ann Arbor, MI 48109, USA. E-mail: lizuwang@umich.edu

${ }^{\dagger}$ The contribution of Jana Stewart was prepared as part of her official duty as a US Government employee.
}

lotic to lentic systems; inundate terrestrial landscapes; modify the export of water, sediment and nutrients to downstream systems; alter fluvial thermal regimes; disconnect river segments from their floodplains, riparian zones and adjacent wetlands; and change the overall physical, chemical and biological structure and function of river systems. Managing for the pervasive influence of dams and their complex suite of stressors requires thorough knowledge of how rivers are influenced by individual dams along with an understanding of how multiple dams located throughout river networks impact system-wide ecological integrity.

Local and site-specific negative impacts of individual dams in both upstream and downstream directions have been well studied (e.g. Pringle et al., 2000; Lessard and Hayes, 2003; Greathouse et al., 2006). However, effects on river networks as well as cumulative impacts of dams have received relatively less attention. Examples include an evaluation of relationships between fish species richness in first-order streams and the number of low-head dams downstream statewide in Wisconsin (Cumming, 2004); a comparison of differences in aquatic biota, habitat and water 
quality between free-flowing reaches versus sections fragmented by 15 dams in Illinois (Santucci et al., 2005); an analysis of regional relationships between dams and 41 fish species in Hokkaido, Japan (Fukushima et al., 2007); and a modelling of impacts of dams on six redhorse fish species in the Grant River watershed in Ontario, Canada, which contains 136 dams (Reid et al., 2008).

Although some of the local ecological effects of altered hydrological connectivity by dams are increasingly understood, indirect biogeochemical effects of dams on river systems are more elusive and difficult to identify (Pringle, 2003). For a single dam, for example, assessment of conditions immediately upstream or downstream from the dam may reveal the degree to which characteristics such as thermal regimes, nutrient concentrations and physical habitat may be altered compared to pre-dam conditions. However, it is challenging to consider the spatial extent of such effects throughout an entire river network. Evaluation of the cumulative biotic effects of hydrologic alterations within an entire river basin or ecological region and consideration of bioassessment criteria of hydrologic effects in addition to presence/absence information on specific taxa or habitat are two of the highly needed research areas (Pringle et al., 2000).

Assessing cumulative impacts of dams on an entire basin or a region presents many challenges. One of the challenges is the difficulty in identifying proper biological indicators that integrate biological, physicochemical and hydrologic impacts of dams. Fish species richness and species presence/ absence are the most commonly used indicators to assess dam impacts (e.g. Cumming, 2004; Fukushima et al., 2007; Reid et al., 2008). However, other indicators for environmental assessment, such as diversity indices and the index of biotic integrity (IBI) have rarely been applied for assessing cumulative dam impacts, although IBI has been commonly used for assessing other sources of human impairment to rivers (e.g. Lyons et al., 2001; Wang et al., 2008). IBIs have also been proven useful in a dam removal assessment (Kanehl et al., 1997) and in comparing fish assemblages between impounded and free-flowing river segments (Santucci et al., 2005). Additionally, fish groups that characterize river segment types (Brenden et al., 2008) may provide insightful information on how dams in river networks may cumulatively modify fish assemblages, which has rarely been reported in previous studies.

Another challenge is that the characteristics of biological indicators for assessing dam impacts are not only affected by dams, but also are influenced by natural variations in thermal and flow regimes, physicochemical habitats and biological structures. Human induced factors other than dams, such as watershed land use, point source pollution and river channel and floodplain modification also affect the characteristics of indicators and obscure the identification of impacts of dams on aquatic ecosystems.
To evaluate regional cumulative biotic effects of hydrologic alterations from dams using biological indicators, we evaluated the impacts of dams on river fish assemblages in the states of Michigan and Wisconsin using multiple fish indicators and multiple approaches to distinguish the influences of dams from those of other natural and humaninduced factors. Our objectives were to assess the relative importance of dams in influencing fish measures compared to other natural and human-induced factors, examine relations among dam measures and fish indicators, and evaluate the overall impacts of dams on fish indicators.

\section{METHODS}

Study streams, catchments, and network and landscape data

The study area included the entire states of Michigan and Wisconsin. Streams identified from the 1:100000 scale National Hydrography Dataset (NHD) were divided into individual stream reaches defined as inter-confluence stretches of water. For each reach, we delineated catchment boundaries that encompassed the entire upstream area draining to the downstream end of each reach using a geographic information system (ESRI, 2002). This database included 28889 reaches and 77972 stream kilometres in Michigan, and 35799 reaches and 87053 stream kilometres in Wisconsin.

A suite of natural and anthropogenic landscape and stream network variables known to influence fish assemblages (Wang et al., 2003a; Wang et al., 2008) were attributed to each reach. Landscape descriptors, including catchment area, mean soil permeability, surficial geology types, 20-year July mean air temperature, 20-year mean precipitation and land uses within catchments were attributed to each reach based on data layers from each state. Stream channel descriptors, including Shreve linkage numbers for each reach, linkage number for the downstream reach that each reach flows into, reach gradient, total upstream stream length and distances from upstream most headwaters and from the Great Lakes or Mississippi River, were calculated using ArcInfo (ESRI, 2002). July mean water temperature was predicted for stream reaches using statistical models developed from measurements made at a subset of the reaches (Wehrly et al., 2009). See Brenden et al. (2006) for additional details regarding methods for stream reach identification, spatial boundary delineation, source data acquisition and variable attribution to the stream reaches. Hereafter, these variables are referred to as environmental factors.

\section{Dam data}

Dam localities for Michigan were obtained from a database that was originally developed by the Michigan 
Department of Water Quality that included all dams in the state in the year 2000, with location correction made by the Institute for Fisheries Research at Ann Arbor in 2004 (authors' unpublished data, 2004). Dam localities for Wisconsin were obtained from a database developed by the Wisconsin Department of Natural Resources (DNR) that included all dams in the state (Wisconsin DNR unpublished data, 2005). We attributed dam locations to the stream reaches for only those that had matching water features on the 1:100000 scale NHD layer for both states, which consisted of 1553 dams in Michigan and 3662 dams in Wisconsin.

For each stream reach, we calculated the distance from the upstream end of each reach to the nearest upstream dam and distance from the downstream end of each reach to the nearest downstream dam along the mainstem (based on stream length) of each stream. We also calculated total numbers of dams downstream on the mainstem and total numbers of dams upstream throughout the stream network, numbers of dams in the upstream stream network and downstream mainstem per unit stream length (i.e. dam density), and lengths of stream segments that were free of dams for each reach (sum of reach length and the distances to nearest upstream and downstream dams). We chose these dam measures as they summarize fragmentation patterns throughout stream networks and because they may be effective at quantifying regional cumulative effects of dams (Table I).

\section{Fish data}

Fish data for Michigan were from the Michigan DNR Fish Collection System and Michigan River Inventory databases (Seelbach and Wiley, 1997). From these databases, we used stream sites where fish were collected using backpack, towbarge, boom electrofishing units, or rotenone from May to October between 1982 and 2007. Data collected by rotenone were corrected for comparability with the rest of the electrofishing data using sampling sites that had both electrofishing and rotenone data (Seelbach et al., 1994; T.
Zorn personal communication). Fish data for Wisconsin were from Wisconsin DNR Fish and Habitat Database and data managed by the Bureau of Science Service. From these databases, we used stream sites where fish were collected using backpack, tow-barge or boom electrofishing units from late May to early October between 1990 and 2004. The lengths of wadeable streams sampled for both states were between 80 and $960 \mathrm{~m}$ (median $=156 \mathrm{~m})$ depending on the size of the streams. The length for all non-wadeable sites sampled was $1610 \mathrm{~m}$. Fish data were collected using singlepass sampling to collect all fish observed, and all captured fish were identified, counted and weighed in the field.

Fish data were summarized by 39 fish indicator variables. These included functional metrics describing species' thermal and feeding preferences, reproductive strategies, habitat preferences and tolerance to stressors; taxonomic summaries including assemblage diversity and number of sport fishes; and IBI scores. We calculated IBI scores for coldwater stream sites defined by the states' trout stream classification using the Wisconsin's coldwater IBI procedure (Lyons et al., 1996) and for non-wadeable rivers using the non-wadeable river IBI procedure (Lyons et al., 2001). For Wisconsin, the wadeable warmwater IBI scores were calculated using the procedure developed specifically for Wisconsin (Lyons, 1992). For Michigan, the wadeable warmwater IBI scores were calculated using a procedure developed by the MDEQ (http://www.deq.state.mi.us/documents/deq-swq-gleas-proc51.pdf) and modified to adjust for stream size and ecoregion influences (Wang et al., 2008). For stream reaches classified as marginal trout streams, we calculated both coldwater and warmwater IBI scores for each state separately and used the higher of the two because a coolwater IBI does not yet exist for the study region. The indicators of thermal, feeding, tolerance and reproduction classifications were based on Lyons (1992) and Lyons et al. (1996, 2001); the habitat preference indicators were based on a river classification framework developed for Michigan (Brenden et al., 2008); sport fishes (excluding sunfish, crappies and yellow perch) were defined by the two state fisheries agencies as riverine game species; and the fish

Table I. Statistical summaries for dam variables. The distances are measured based on river reaches that are defined between confluences

\begin{tabular}{lccc}
\hline Dam measures & Mean & Minimum & Maximum \\
\hline Distance of river free of dam (km, Dfds) & 41 & 1 & 218 \\
Distance to a downstream dam (km, Dtdndm) & 26 & 0 & 183 \\
Distance to an upstream dam (km, Dtupdm) & 11 & 0 & 134 \\
Downstream dam density (number/km, Dndmd) & 0.04 & 0.00 & 3.00 \\
Downstream dam abundance (number, Dndm\#) & 5 & 0 & 48 \\
Upstream dam density (number/km, Updmd) & 0.03 & 0.00 & 1.20 \\
Upstream dam abundance (number, Updm\#) & 22 & 0 & 980 \\
\hline
\end{tabular}

Distance to a downstream dam $=0$ means that there is a dam at the river reach downstream of the target reach, and distance to an upstream dam $=0$ means that there is a dam at the river reach upstream of the target reach. River reaches with dams are excluded. STD $=$ standard deviation 
diversity indicator was based on Shannon index of diversity (Magurran, 1988).

\section{Data analyses}

For all analyses, we excluded stream sites that had greater than $60 \%$ agricultural or $10 \%$ urban land uses in their upstream catchments to minimize the potential for severely altered landscape conditions to mask our ability to detect relationships between fish indicators and dam measures (Wang et al., 1997, 2003b, 2008). As a result, our analyses included 690 of the 814 stream reaches in Michigan and 537 of the 761 stream reaches in Wisconsin where fish assemblage data were available (Figure 1).

To identify potential fish indicators of dam impacts, we first correlated fish and dam measures using Spearman rank correlations (SAS, 2003). We used a non-parametric approach because the majority of data distributions failed to meet the assumption of normality after various attempts at transformations. The significance of correlations was adjusted using a Bonferroni correction to minimize the influence of a large sample size on the likelihood of obtaining a significant $p$-value. Fish indicators that were significantly correlated with dam measures were then divided into a biotic-integrity group and a habitat-andsocial-preference group. The former was a group of IBI metrics that was used to measure human degradation on fish biotic integrity (Lyons, 1992; Lyons et al., 1996; Lyons et al., 2001), and the latter was a group of measures that was used to represent stream types (Brenden et al., 2008) and social and economic values (Table II). The purpose of this correlation analysis was not only to potentially reduce the number of fish indicators, but also to identify which fish indicators were correlated with different dam measures.

To select those fish indicators and environmental factors that were most sensitive to dam impacts, we used canonical correspondence analysis (CCA) automatic variable selection

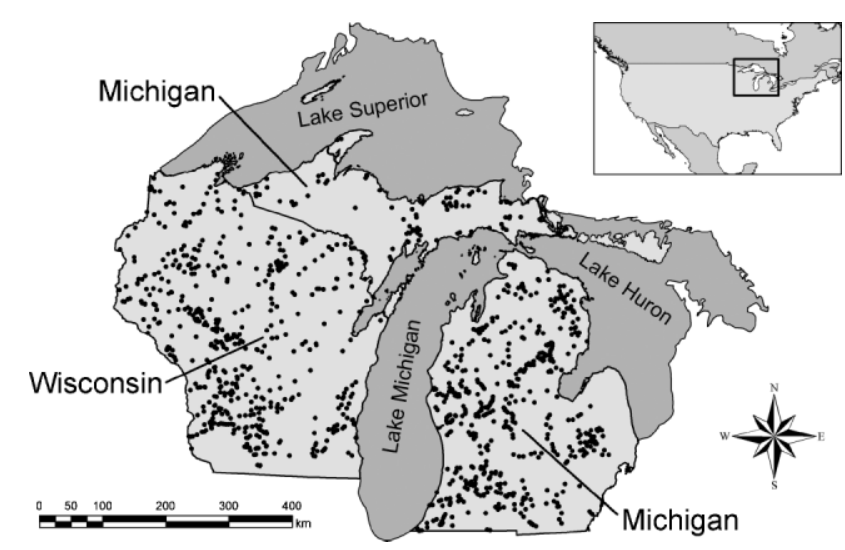

Figure 1. Fish sampling sites in Michigan and Wisconsin procedures using CANOCO software (ter Braak and Smilauer, 1998). We first identified the key fish indicators that most strongly correlated with dam measures (Monte Carlo Permutation tests, $p<0.05)$. In the CCA processes, we used dam measures as 'independent variable data source' and fish indicators as 'dependent variable data source' for the two groups of fish indicators separately. We then identified the key environmental factors (non-dam measures) that most strongly correlated with fish indicators (Monte Carlo Permutation tests, $p<0.05$ ). In these CCA processes, we used the selected fish indicators as 'independent variable data source' and the environmental factors as 'dependent variable data source' for the two groups of fish indicators separately.

To assess the importance of dams in influencing fish assemblages, we estimated the relative importance of dam measures and the selected environmental factors in explaining the variances in the two groups of selected fish indicators. We included both natural and human-induced factors in our environmental factor dataset in this analysis to identify the relative importance of dams compared to the other factors in influencing fish indicators. We partitioned the total variance of fish indicators explained by all the factors into dam measures, environmental factors and interactive terms using CANOCO software (ter Braak and Smilauer, 1998).

To evaluate relationships among dam measures and fish indicators, we conducted CCA analyses again on dam measures, the selected fish indicators and the selected environmental factors using CANOCO software (ter Braak and Smilauer, 1998). We plotted the first and second CCA axes scores to examine the dominant effects of dam measures on fish indicators when the environmental factors were also taken into account.

To evaluate the overall impacts of dams on fish indicators, we first divided our stream sites into four groups based on equal intervals (i.e., quartiles) of each dam measure that was below the 99th percentile (Table III). We included the values of each dam measure that were greater than the 99th percentile in the group that had the highest values of each dam measure to reduce the influence of the extreme values on the grouping. We then tested whether the fish indicator values were different among the four groups of each dam measure using Wilcoxon tests (SAS, 2003). We last qualitatively evaluated the trends in relationships between dam measures and fish indicators by visually examining their plots. We used non-parametric tests because of the nonnormal distribution and uneven sample size of our data. This procedure included only fish indicators that showed the strongest association with dam measures in our previous steps. To minimize the influence of stream size on our analyses, values of fish indicators other than IBI scores were standardized by dividing the values by natural $\log$ of stream 
Table II. Spearman correlation coefficients between fish and dam measures. All fish indicators are significantly correlated ( $p<0.05$, adjusted using Bonferroni correction for sample size) with at least one dam measure

\begin{tabular}{|c|c|c|c|c|c|c|c|}
\hline \multirow[t]{2}{*}{ Fish indicators } & \multicolumn{7}{|c|}{ Dam measures } \\
\hline & Dfds & Dndm\# & Dndmd & Dtdndm & Dtupdm & Updm\# & Updmd \\
\hline \multicolumn{8}{|l|}{ Biotic-integrity-indicator group } \\
\hline Coldwater species richness & - & -0.33 & -0.23 & - & - & -0.26 & - \\
\hline Carnivores (Carnab, \#/100 m) & - & -0.21 & -0.16 & - & - & - & - \\
\hline Coldwater (\#/100 m) & - & -0.23 & -0.16 & - & - & -0.31 & -0.13 \\
\hline Index of biotic integrity (IBI) & 0.16 & -0.17 & -0.34 & 0.13 & 0.17 & 0.48 & - \\
\hline Invertivores abundance $(\# / 100 \mathrm{~m})$ & - & 0.19 & 0.14 & - & - & - & - \\
\hline Intolerance abundance (Intoab, \#/100 m) & - & - & -0.13 & - & - & 0.30 & - \\
\hline Intolerant species richness & - & - & - & - & 0.29 & 0.46 & 0.25 \\
\hline Lithophytes abundance (\#/100 m) & - & - & - & - & 0.15 & 0.14 & 0.14 \\
\hline Native species richness (Nativsp) & - & 0.14 & - & - & 0.30 & 0.52 & 0.34 \\
\hline Omnivores abundance $(\# / 100 \mathrm{~m})$ & - & 0.18 & 0.16 & - & 0.14 & - & 0.15 \\
\hline$\%$ carnivores abundance (Carn\%) & - & -0.35 & -0.23 & - & - & - & - \\
\hline$\%$ coldwater fish abundance (Cold\%) & - & -0.27 & -0.18 & - & - & -0.34 & -0.16 \\
\hline$\%$ intolerances abundance (Into\%) & - & -0.33 & - & - & - & - & - \\
\hline$\%$ invertivores abundance (Inver\%) & - & 0.18 & - & - & - & 0.27 & 0.13 \\
\hline$\%$ lithophytes abundance (Lith\%) & - & - & - & - & 0.27 & 0.43 & 0.24 \\
\hline$\%$ omnivores abundance $(\mathbf{O m i n} \%)$ & - & - & 0.21 & - & - & 0.20 & 0.28 \\
\hline$\%$ tolerance abundance & - & 0.20 & 0.16 & - & - & -0.18 & - \\
\hline$\%$ trout abundance & - & -0.30 & -0.21 & - & - & -0.31 & -0.14 \\
\hline Shannon diversity index (Divers) & 0.15 & - & - & - & 0.33 & 0.47 & 0.27 \\
\hline Sucker abundance $(\# / 100 \mathrm{~m})$ & - & 0.34 & 0.19 & - & - & 0.31 & - \\
\hline Sucker species richness & - & 0.36 & - & - & - & 0.19 & - \\
\hline Total fish species richness & 0.13 & - & - & - & 0.33 & 0.33 & 0.33 \\
\hline \multicolumn{8}{|l|}{ Habitat-social-preference group } \\
\hline$\%$ headwater species (Hdwsp\%) & - & 0.15 & 0.15 & - & -0.24 & -0.48 & -0.20 \\
\hline$\%$ headwater fish abundance (Hdwab\%) & - & 0.21 & 0.18 & - & -0.15 & -0.33 & - \\
\hline$\%$ large-river fish abundance & - & - & - & - & 0.21 & 0.64 & 0.28 \\
\hline$\%$ large-river species (Lrsp\%) & - & - & - & - & 0.20 & 0.64 & 0.29 \\
\hline$\%$ midsize-river species & - & 0.13 & - & - & 0.19 & 0.16 & 0.33 \\
\hline$\%$ midsize-river fish & - & 0.16 & - & - & 0.17 & 0.34 & 0.21 \\
\hline$\%$ salmonids abundance & - & -0.34 & -0.23 & - & - & -0.31 & -0.15 \\
\hline$\%$ sport-fish abundance (Sportab\%) & - & - & - & - & 0.20 & 0.56 & 0.29 \\
\hline Headwater fish (Hdwab, \#/100 m) & - & 0.38 & 0.20 & - & - & -0.53 & - \\
\hline Headwater species richness & - & 0.21 & 0.15 & - & - & -0.14 & - \\
\hline Large-river fish (Lrab, \#/100 m) & - & - & - & - & 0.20 & 0.63 & 0.29 \\
\hline Large-river species richness & - & - & - & - & 0.21 & 0.64 & 0.29 \\
\hline Midsize-river fish (Mrab, \#/100 m) & - & 0.18 & - & - & 0.16 & 0.51 & 0.19 \\
\hline Midsize-river species richness (Lrsp) & - & 0.16 & - & - & - & 0.21 & 0.18 \\
\hline Salmonids abundance (Salmon, \#/100 m) & - & -0.29 & -0.21 & - & - & -0.29 & - \\
\hline Sport-fish abundance (Sportab,\#/100 m) & - & - & - & - & 0.17 & 0.48 & 0.28 \\
\hline Total fish abundance (Tfisab, \#/100 m) & - & 0.33 & - & - & - & -0.46 & - \\
\hline
\end{tabular}

Abbreviations in the parentheses (in bold) were fish indicators selected by the CCA analysis. See Table I for the abbreviations for dam measures

linkage number +1 . The influences of stream size on IBI scores had already been taken into account in the IBI calculating process (Lyons, 1992; Lyons et al., 2001).

\section{RESULTS}

All 39 fish indicators were significantly correlated $(p<0.05)$ with at least one of the dam measures (Table II). Numbers of downstream mainstem dams and of upstream network dams correlated with the most fish indicators $(67 \%$ and $87 \%$ correlations significant), and length of stream segment without a dam (10\%) and distance to nearest downstream dam $(3 \%)$ correlated with the fewest. The CCA automatic variable selection procedures selected 11 fish indicators that were most strongly correlated with dam measures (Table II, Monte Carlo Permutation tests $p<0.05$ ) for each of the biotic-integrity and habitat-and-social-preference groups. 
Table III. Values for the four levels of the dam measures used for Table V and Figures 4-6, which were determined based on quartile breaks in the data falling below the 99th percentile

\begin{tabular}{llcc}
\hline Dam measures & Low & Mid-low & Mid-high \\
\hline Distance of river free of dam (km, Dfds) & $<50$ & $50-100$ & $100-150$ \\
Distance to a downstream dam (km, Dtdndm) & $<40$ & $40-80$ & $80-120$ \\
Distance to an upstream dam (km, Dtupdm) & $<20$ & $20-40$ & $40-60$ \\
Downstream dam density (number/km, Dndmd) & $<0.07$ & $0.07-0.14$ & $>150$ \\
Downstream dam abundance (number, Dndm\#) & $<10$ & $10-20$ & $>120$ \\
Upstream dam density (number/km, Updmd) & $<0.10$ & $0.10-0.20$ & $20-30$ \\
Upstream dam abundance (number, Updm\#) & $<200$ & $200-400$ & $0.20-0.30$ \\
P & & $400-600$ & $>0.21$ \\
\hline
\end{tabular}

The CCA automatic variable selection procedures also identified 13 and 17 of the environmental factors that were significantly (Monte Carlo Permutation tests, $p<0.05$ ) correlated to the selected biotic-integrity and habitat-andsocial-preference fish indicators, respectively (Table IV).

CCA variance partitions indicated that dam measures and environmental factors together explained $37 \%$ of the variation for the biotic-integrity indicators and $53 \%$ of the variation for the habitat-and-social-preference indicators. Of the explained variation, dam measures explained $16 \%$ and the environmental factors explained $71 \%$ for the bioticintegrity indicators, and dam measures explained $19 \%$ and the environmental factors explained $63 \%$ for the habitat- and-social-preference indicators (Figure 2). The remaining variance in fish indicators was explained by the interactions among the dam measures and the environmental factors.

The plot from CCA analyses for the selected bioticintegrity indicators, the dam measures and the selected environmental factors indicated that both dam measures and the environmental factors were strongly related to fish indicators. In general, upstream network dam density, length of stream segments without a dam and distance to a downstream dam were positively associated with IBI scores and negatively associated with percent omnivorous fish abundance (Figure 3A). In contrast, downstream dam density was negatively associated with IBI and positively

Table IV. Statistical summaries for environmental variables included in this study

\begin{tabular}{|c|c|c|c|}
\hline Environmental factors & Mean & Range & STD \\
\hline Catchment area $\left(\mathrm{km}^{2}\right)^{\mathbf{1 , 2}}$ & 959 & $1-30905$ & 3767 \\
\hline Catchment slope (degree) & 2 & $0-12$ & 2 \\
\hline Catchment medium texture geology $(\%)$ & 14 & $0-100$ & 27 \\
\hline Catchment fine texture geology $(\%)^{2}$ & 14 & $0-100$ & 32 \\
\hline Catchment peat and muck texture geology $(\%)$ & 2 & $0-82$ & 7 \\
\hline Catchment coarse texture geology $(\%)^{1,2}$ & 59 & $0-100$ & 40 \\
\hline Catchment forest land cover $(\%)^{1,2}$ & 38 & $0-97$ & 24 \\
\hline Catchment water and wetland land cover $(\%)^{\mathbf{1 , 2}}$ & 15 & $0-87$ & 12 \\
\hline Catchment urban land use $(\%)^{\mathbf{1 , 2}}$ & 4 & $0-90$ & 8 \\
\hline Catchment agricultural land use $(\%)^{\mathbf{1 , 2}}$ & 33 & $0-95$ & 27 \\
\hline Catchment soil permeability $(\mathrm{cm} / \text { hour })^{\mathbf{1 , 2}}$ & 13 & $1-33$ & 8 \\
\hline Distance to headwater $(\mathrm{km})^{\mathbf{1 , 2}}$ & 43 & $0-686$ & 94 \\
\hline Distance to Great Lakes or Mississippi River $(\mathrm{km})^{2}$ & 119 & $0-665$ & 107 \\
\hline Immediate downstream reach Shreve linkage number ${ }^{\mathbf{1 , 2}}$ & 129 & $0-4296$ & 472 \\
\hline Immediate downstream reach stream order & 3.3 & $1-7$ & 1.2 \\
\hline Reach July mean air temperature $\left({ }^{\circ} \mathrm{C}\right)$ & 21 & $18-23$ & 1 \\
\hline Reach growing degree days $\mathbf{1 , 2}$ & 2,319 & $1480-3110$ & 394 \\
\hline Reach precipitation $(\mathrm{mm})^{2}$ & 822 & $717-1009$ & 51 \\
\hline Reach predicted July mean water temperature $\left({ }^{\circ} \mathrm{C}\right)^{\mathbf{1 , 2}}$ & 20 & $4-34$ & 4 \\
\hline Reach Shreve linkage number ${ }^{1,2}$ & 103 & $1-4296$ & 455 \\
\hline Reach stream order & 2.7 & $1-7$ & 1.3 \\
\hline Reach gradient $(\mathrm{m} / 100 \mathrm{~m})^{\mathbf{1 , 2}}$ & 0.3 & $0-6.6$ & 0.5 \\
\hline Total upstream network river length $(\mathrm{km})^{2}$ & 554 & $1-19957$ & 2246 \\
\hline
\end{tabular}

${ }^{1}$ and ${ }^{2}$ indicate environmental factors that were significantly correlated with biotic-integrity and habitat-and-social-preference fish indicators, respectively, and were selected by the canonical correspondence analysis variable selection processes and were used for variance portioning analysis 


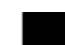

Dam measures

Other environmental factors

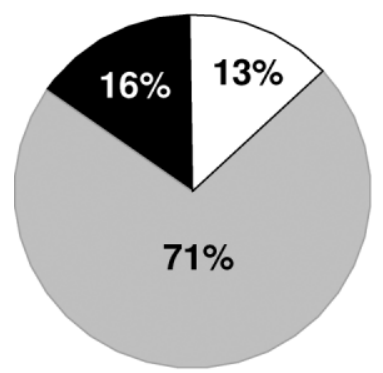

\section{Fish biotic-integrity} measures

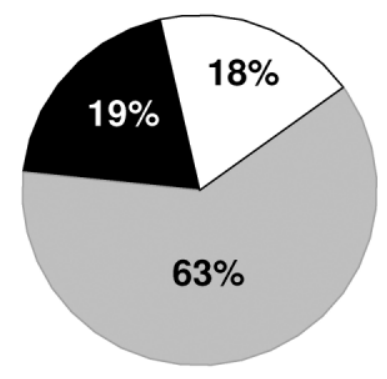

Fish habitat-preference measures

Figure 2. Percentages of explained variance in fish indicators that were contributed by dams, the other environmental factors and the interaction between dams and the other environmental factors. All factors together explained $37 \%$ variation for the biotic-integrity indicators and $53 \%$ variation for the habitat-and-social-preference indicators

associated with percent omnivorous abundance. Distance to downstream dam was positively associated with percent intolerant, carnivorous and coldwater fish abundances, while number of downstream dams showed the opposite trends. Number of upstream dams generally positively associated with number of native fish species, fish diversity and IBI score. The association among fish indicators and the other environmental factors were along thermal, stream-size and land-use gradients. Based on these results, we selected number of native fish species, diversity index and IBI from the biotic-integrity group as the key fish indicators for assessing impacts of dams in our subsequent analysis step. We chose IBI instead of individual metrics because IBI integrated the other fish indicators and showed moderate association with dam measures.

The plot from CCA analyses for the selected habitat-andsocial-preference fish indicators, the dam measures and the selected environmental factors also indicated that both dam measures and the other environmental factors were strongly related to fish indicators. Number of upstream dams was strongly positively associated with large river fish measures (Figure 3B). Distance to an upstream dam and length of stream segment free of dams were moderately positively associated with sport-fish measures, while distance to downstream dams was weakly associated with total fish abundance. Downstream dam density and number of downstream dams were associated with headwater fish and salmonid indicators. Upstream dam density did not show a clear association with any fish indicators. The association among habitat-and-social-preference fish indicators and the other environmental factors were mainly along thermal and stream-size gradients. Based on these results, we selected abundances of headwater, midsize-river,

large-river, salmonid, sport-fish and all fishes from the habitat-and-social-preference group as the key fish indicators for assessing impacts of dams in our next analysis step.

Tests on the differences in the selected fish indicators among the four levels of each dam measure indicated that 5 of the 63 fish indicator-dam measure pairs showed significant and positive associations, 36 showed negative associations and 22 showed no or inconclusive associations (Table V, Figures 4-6). IBI was positively associated with the three measures for distance of river without a dam or distance to a dam and negatively associated with downstream dam density and amount. IBI was positively associated with number of upstream dams, but had no significant relation with upstream dam density. Both number of native species and the diversity index were negatively associated with the distance of river without a dam, distance to an upstream dam, downstream dam density, and total number of upstream dams, and had no significant association with distance to a downstream dam, total number of downstream dams and upstream dam density. The abundance of headwater fishes was negatively associated with distance of river without a dam, distance to a dam, and upstream dam abundance, and positively associated with downstream dam abundance. The abundance of midsize and large river fishes was negatively associated with the densities and abundances of both upstream and downstream dams, but had no clear relation with the three measures for distance of river without a dam or distance to a dam. The abundance of salmonids and sport fishes was negatively associated with density and abundance of downstream dams, and abundance of upstream dams. The abundance of salmonid fishes was negatively associated with the distance to an upstream dam, but abundance of sport fishes was negatively associated with the distance to a downstream dam. The abundance of all fishes negatively associated with all dam measures, except for downstream dam density. The relationship trends were unclear for associations between midsize-river fish abundance and distance to an upstream dam, large-river fish abundance and distance to a downstream dam, and total fish abundance and downstream dam density, although they were statistically significant (Table V, Figures 4-6).

The total number of upstream dams was significantly associated with the most (9 of 9), and upstream dam density associated with the least (3 of 9) number of the selected fish indicators. Downstream density and abundance were clearly associated with seven, distance to an upstream dam associated with six, distance of river free of dams associated with five and distance to a downstream dam associated with four of the selected nine fish indicators (Table V, Figures 4-6).

The results from the Spearman rank correlation analyses, when the influence of non-dam environmental factors were not taken into account, were substantially different from the 


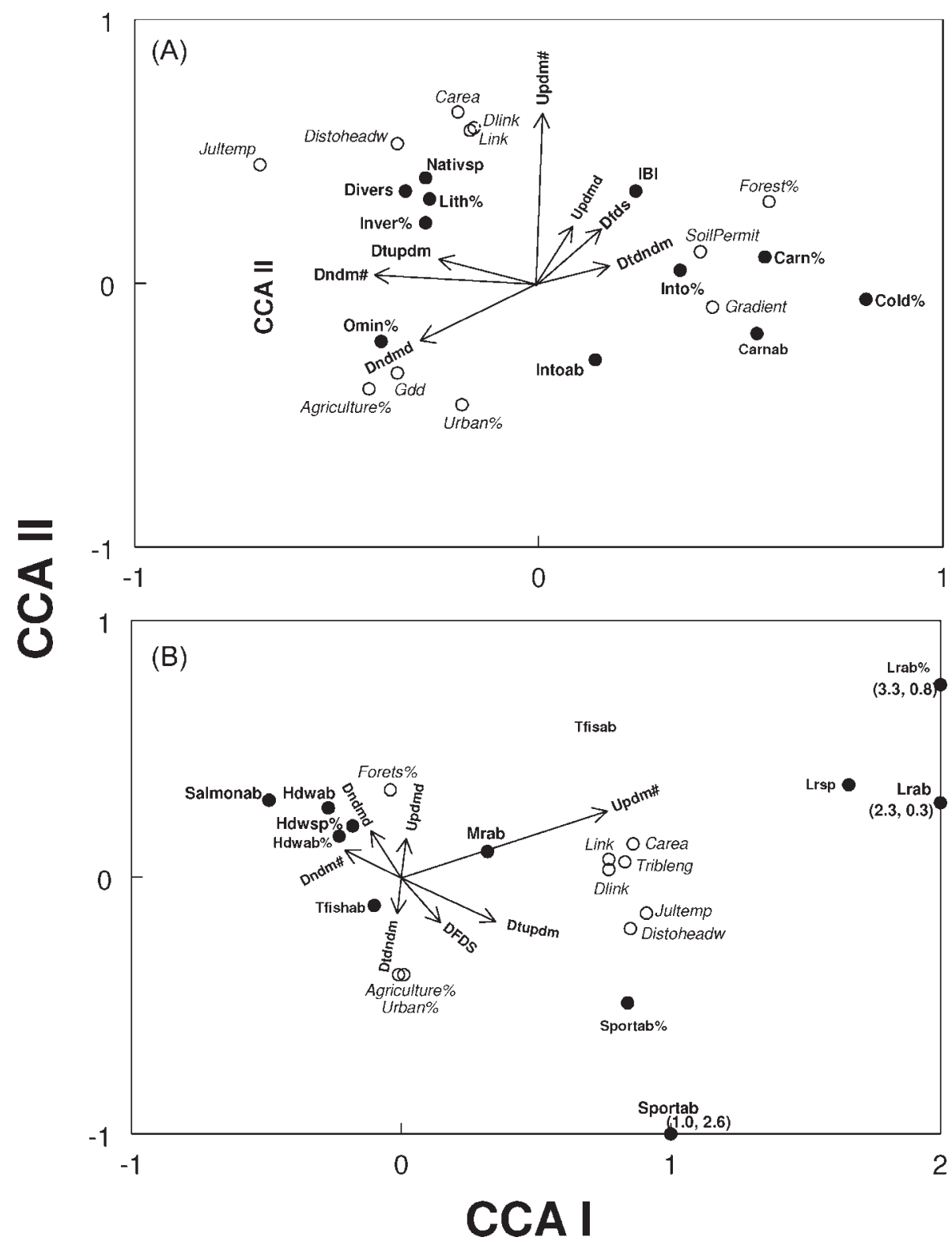

Figure 3. Plots of canonical correspondence analysis axis I versus II for the biotic-integrity indicators (A) and the habitat-and-social-preference indicators (B). Abbreviations for dam measures and fish indicators were listed in Tables I and II. Agriculture $\%=\%$ catchment agricultural land use, Carea $=$ catchment area $\left(\mathrm{km}^{2}\right)$, Dlink $=$ downstream linkage number, Distoheadw $=$ distance to headwater $(\mathrm{km})$, Forest $\%=\%$ catchment forest land use, Gdd $=$ growing degree days, Gradient $=$ river segment slope, Julytemp $=$ July mean water temperature $\left({ }^{\circ} \mathrm{C}\right)$, Link $=$ stream linkage number, Soilpermit $=$ catchment average soil permeability, Tribleng $=$ total length of upstream tributaries $(\mathrm{km})$ and Urban $\%=\%$ catchment urban land use

results that comparing selected fish indicators among the four-level dam measures when influences of river size were taken into account (Tables II and V). Among the nine selected fish indicators included in both tests, 28 of the 63 fish-dam test pairs $(44 \%)$ were significant in only one of the two test types, 12 of the 63 pairs (19\%) showed opposite fish-dam relationships between the two test types, and only 23 of the 63 pairs (37\%) had the same results for the two test types.

\section{DISCUSSION}

We evaluated the cumulative effects of upstream dams, downstream dams, distance to dams and dam density on multiple fish assemblage measures in the non-impoundment sections of rivers at a multistate spatial scale. Our study has three key findings. First, after accounting for river size and land-use influences, our results clearly demonstrate that dams have significant impacts on fish biotic-integrity and 
Table V. Statistical differences and trends for the representative fish indicators within the four levels of each dam measure (values for the four levels of each dam measure were given in Table III)

Fish measures

Dam measures

\begin{tabular}{|c|c|c|c|c|c|c|c|}
\hline & & & & & & & \\
\hline & Dfds & Dtdndm & Dtupdm & Dndmd & Dndm\# & Updmd & Updm\# \\
\hline Index of biotic integrity & $+^{* *}$ & $+^{* *}$ & $+^{* *}$ & $--^{* *}$ & $-^{* *}$ & - & $+^{* *}$ \\
\hline Shannon diversity index & $-^{* *}$ & - & $-^{* *}$ & $-^{* *}$ & - & - & $-^{* *}$ \\
\hline Number of species & $-{ }^{* *}$ & - & $-{ }^{* *}$ & $-{ }^{* *}$ & - & - & $-{ }^{* *}$ \\
\hline Headwater-fish (\#/100 m) & $-^{* *}$ & $-{ }^{* *}$ & $-^{* *}$ & - & $+^{* *}$ & - & $-^{* *}$ \\
\hline Midsize-river-fish (\#/100 m) & - & - & $*$ & $-^{* *}$ & $-{ }^{* *}$ & $-{ }^{* *}$ & $-^{* *}$ \\
\hline Large-river-fish $(\# / 100 \mathrm{~m})$ & - & $* *$ & - & $-{ }^{* *}$ & $-{ }^{* *}$ & $-{ }^{* *}$ & $-{ }^{* *}$ \\
\hline Salmonid (\#/100 m) & - & - & $-^{* *}$ & $-^{* *}$ & $-^{* *}$ & - & $-^{* *}$ \\
\hline Sport-fish $(\# / 100 \mathrm{~m})$ & - & $-{ }^{* *}$ & - & $-{ }^{* *}$ & $-^{* *}$ & - & $-^{* *}$ \\
\hline All-fish $(\# / 100 \mathrm{~m})$ & $-^{* *}$ & $-{ }^{* *}$ & $-^{* *}$ & * & $-^{* *}$ & $-^{* *}$ & $-^{* *}$ \\
\hline
\end{tabular}

*indicates significant at $p<0.05$ and ${ }^{* *}$ indicates significant at $p<0.01$ for the Wilcoxon tests. + indicates values of fish indicators increase and - indicates values of fish indicators decrease as the values of dam measures increase. - indicates not significant. Without + or - indicates no clear trend. All fish indicators, except the index of biotic integrity scores, were divided by $\ln ($ linkage number +1 ) to correct the effect of stream size. See Table I for the abbreviations for dam measures.

habitat-and-social-preference indicators. Second, environmental factors that influence fish assemblages in addition to dams should be considered when evaluating regional effects of dams on fish assemblages. Without considering such coinfluential factors, evaluations will be inadequate and potentially misleading. Last, at a multistate spatial scale, the role of dams alone in determining fish assemblage composition is relatively small (explained less than 20\% variance) compared with the other environmental factors, such as river size, flow and thermal regimes and land uses jointly. However, our results do indicate that both downstream and upstream dams substantially modify fish assemblages in the non-impoundment sections of rivers. Further, the upstream, downstream and density effects differ among fish indicators, a result with significant implications for maintaining river biotic integrity, protecting biodiversity and managing fisheries.

The substantial difference in results between tests that do not take into account the influence of non-dam environmental factors versus tests that take into account the influence of river size implies that simple correlation results are suitable only for exploratory analyses. These results also emphasize the importance of multivariate analyses and tests of variance among levels of dam measures that can take into account the influences of non-dam environmental factors for evaluating dam effects. However, the associations among fish indicators and dam measures in our CCA plots were weak, and we can only take into account the influences of river size and land uses in our univariate tests, but could not take into account all other covariates. In studying dam impacts on fish species richness for first order streams in Wisconsin, Cumming (2004) found that species richness appeared to decrease as number of downstream dams increased. However, this pattern was strongly co-influenced by downstream linkage number, elevation, distance to a nearest town and northern coordinates. Examining only the relationship between species richness and number of downstream dams could result in misleading conclusions. Fukushima et al. (2007) used a generalized linear regression model approach to identify the influence of dam presence and years of dam isolation on fish species presence/absence. When the dam measures had significant contributions to the regression model, the dam measures were considered having a significant influence on fish. These studies, in corroboration with ours, underscore the challenge of isolating effects of dams on fish assemblages from those resulting from nondam factors.

Our finding that dam measures explained much less variance in fish indicators than all the other environmental factors jointly is consistent with previous findings. Among the few studies evaluating regional impacts of dams, Cumming (2004) reported that number of downstream dams had a significant effect on first order stream fish species richness in Wisconsin, but this effect is small compared with the influence of water quality and summer temperature. He concluded that modifications of water volume and temperature by low-head dams were greater threats to fish assemblages than the decrease in connectivity. Linking human disturbances with species richness of fish, macroinvertebrates and aquatic plants using multiple regression models, Strayer et al. (2003) also found that upstream dam density was ineffective in predicting ecological conditions in streams and rivers in the Chesapeake Bay Watershed. Fukushima et al. (2007) predicted the presence/absence of fish species in Hokkaido, Japan, using a generalized linear model and found that dam occurrence upstream of the fish 

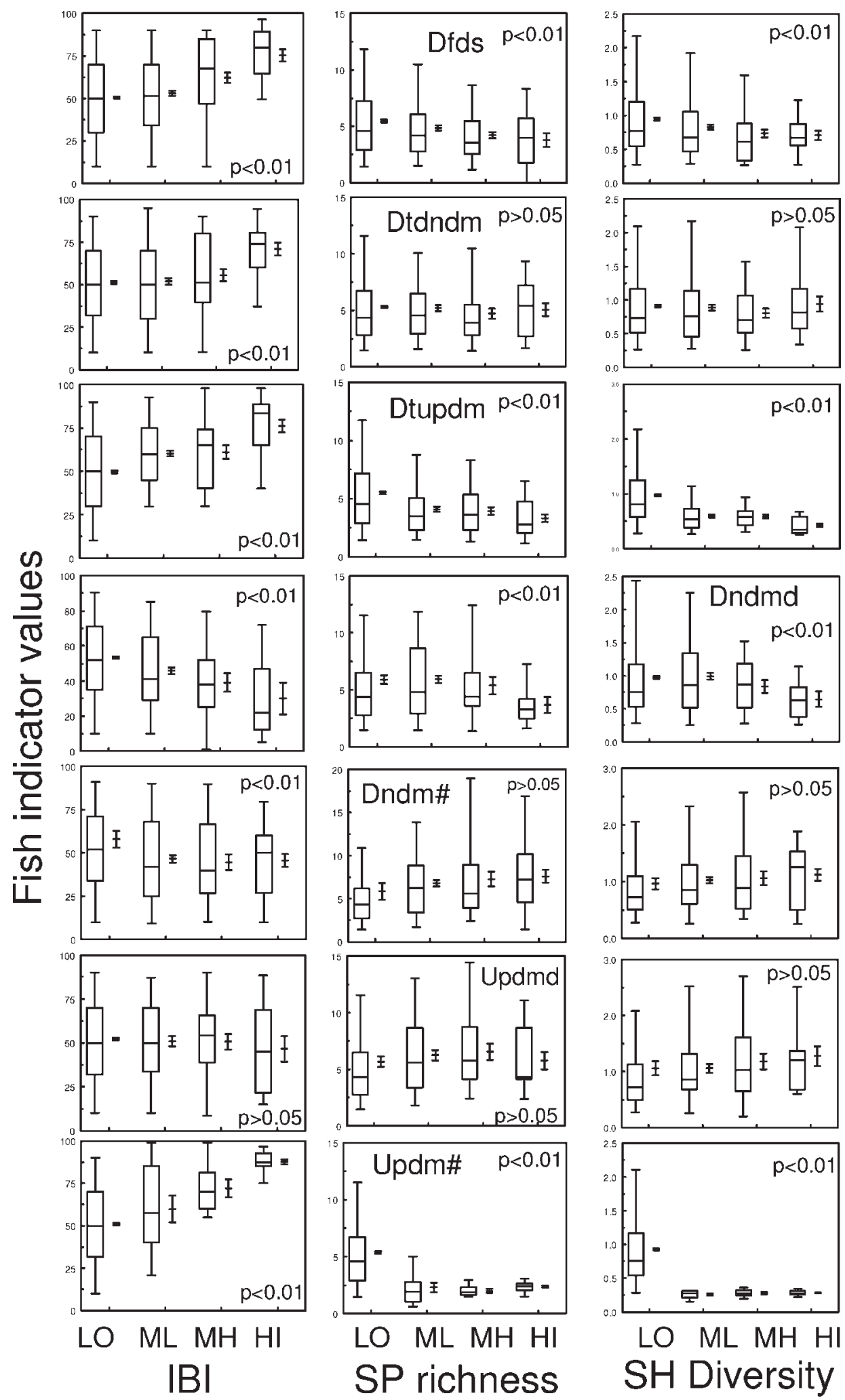
SP richness

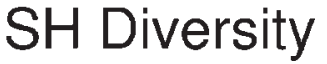

Figure 4. Comparison of fish IBI, native fish species richness (SP richness), and Shannon index of diversity for the four levels of dam measures. LO, ML, MH and HI represent low, mid-low, mid-high and high levels of values for dam measures, respectively. Values for each level of the dam measures were given in Table III. The abbreviations for dam measures are given in Table I. The dam measure for each row was given only in one of the three columns. Error bars represent mean and one standard error. $p$-values are from Wilcoxon tests 


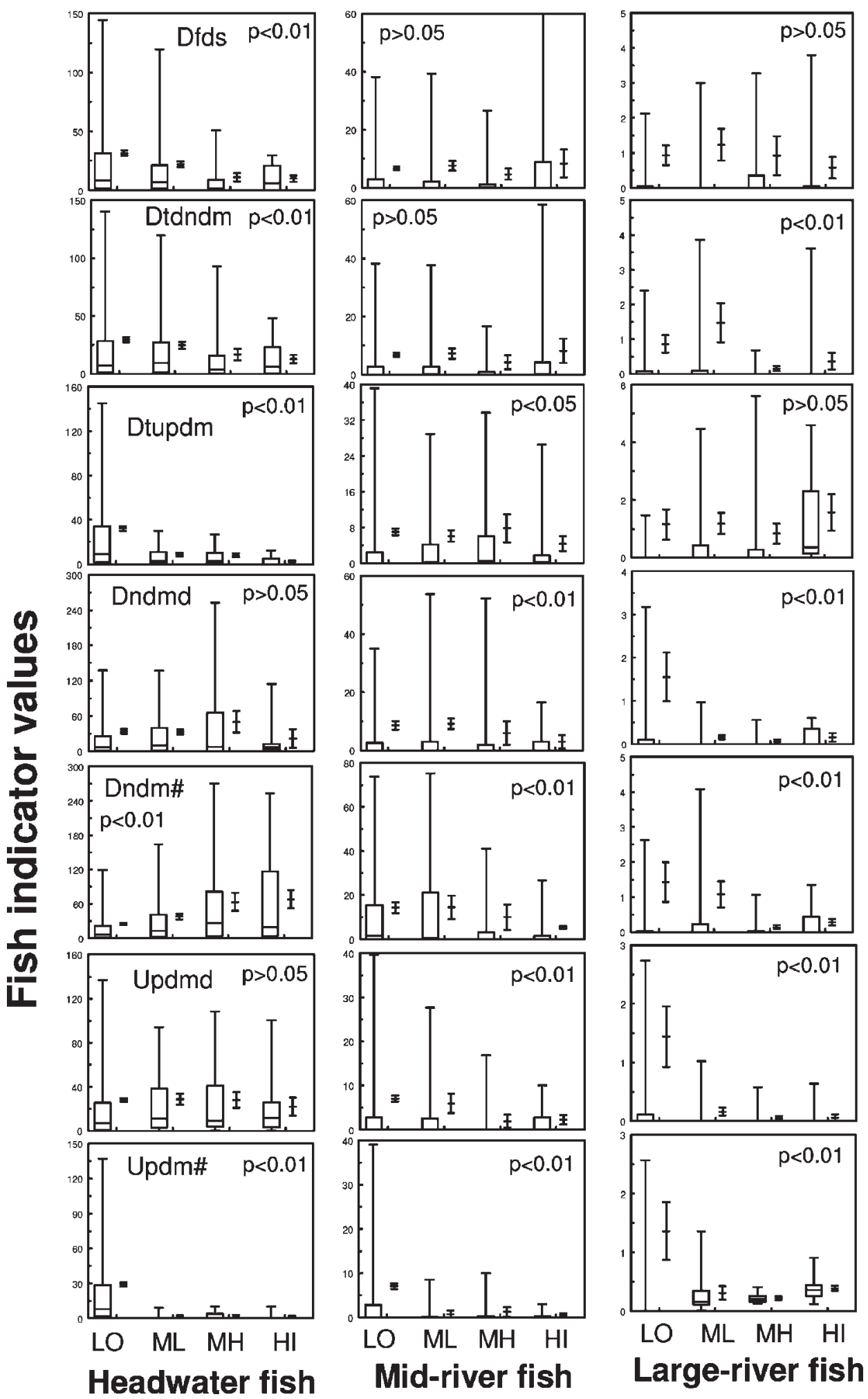

Figure 5. Comparison of headwater, mid-river and large-river fish abundances for the four levels of dam measures. LO, ML, MH and HI represent low, mid-low, mid-high and high levels of values for dam measures, respectively. Values for each level of the dam measures were given in Table III. The abbreviations for dam measures are given in Table I. The dam measure for each row was given only in one of the three columns. Error bars represent mean and one standard error. $p$-values are from Wilcoxon tests 

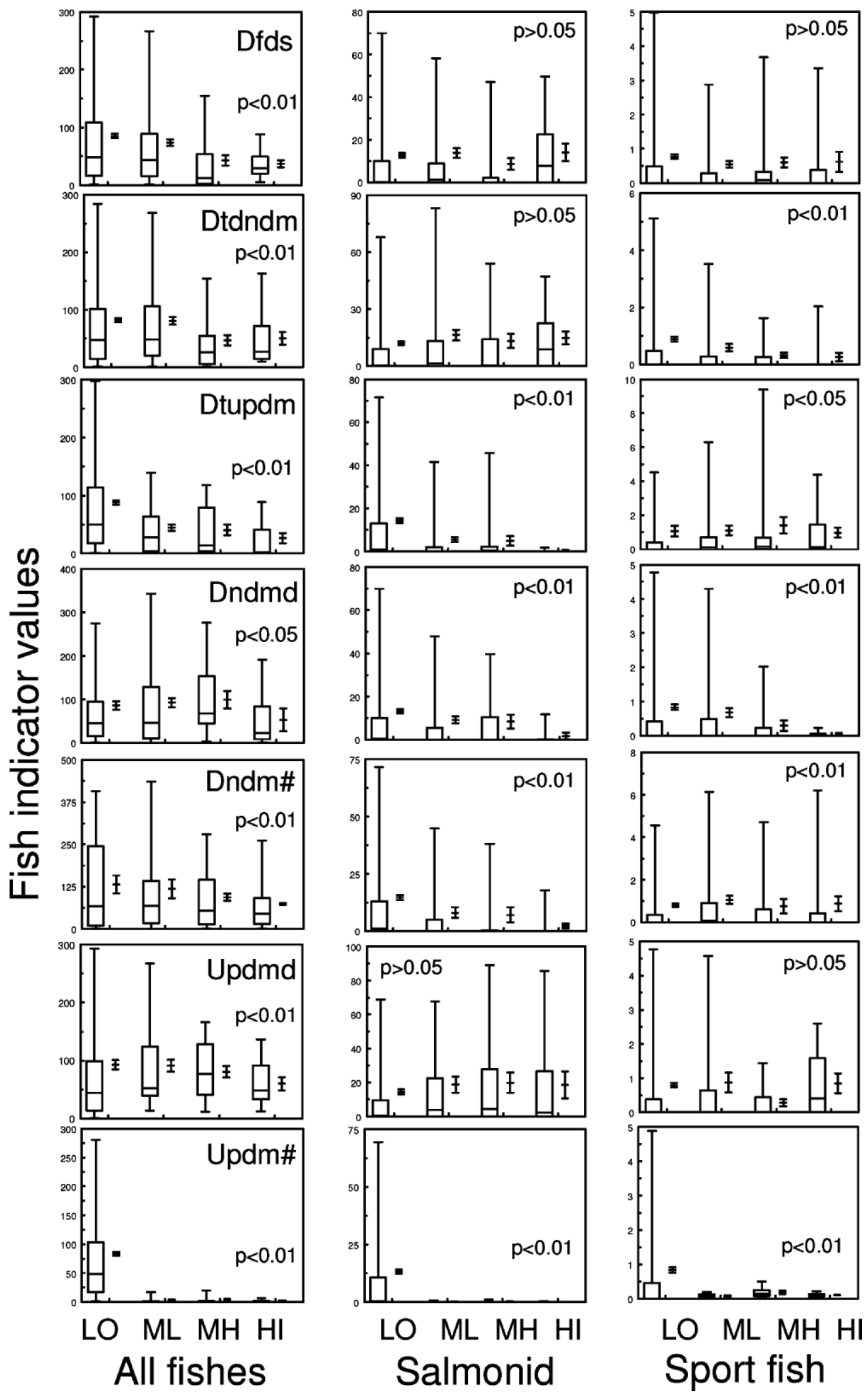

LO ML MH HI Sport fish

Figure 6. Comparison of all fishes, salmonid and sportfish abundances for the four levels of dam measures. LO, ML, MH and HI represent low, mid-low, midhigh and high levels of values for dam measures, respectively. Values for each level of the dam measures were given in Table III. The abbreviations for dam measures are given in Table I. The dam measure for each row was given only in one of the three columns. Error bars represent mean and one standard error. $p$-values are from Wilcoxon tests 
sites and number of years between dam establishment and fish sampling were predictors for only 11 of the 41 individual fish species models. Although the results for the last two studies may be due to the ineffectiveness of multiple regressions for detecting importance of influential factors, all the three previous studies collectively support our conclusion.

Our result that the role of dams in determining fish assemblage composition at a regional scale is small relative to all other environmental factors jointly does not imply that influences of downstream and upstream dams are negligible in determining the region's fish occurrence and abundance. This is because river fish assemblages at a regional scale are largely determined by the interactions of multiple factors, such as zoogeography (e.g. history, climate, natural barriers and connection with large water bodies), physicochemical and biological conditions (e.g. size, thermal and flow regimes, conditions to complete life cycles and others), and human-induced factors (e.g. dam building, agricultural and urban land uses, point-source pollutions, animal grazing and waste disposal and invasive species introductions) that operate at multiple spatial scales (Poff, 1997; Wang et al., 2006). The cumulative impacts of dams are only a part of the multiple components of human-induced factors, and hence the small amount of variance explained by dams is not unexpected. The goal of managing river natural fish assemblages is to maintain the natural zoogeographical and physicochemical conditions by minimizing the influence of human-induced factors. The effects of dams on fish assemblages are one of the most important human-induced factors that can potentially be minimized by science-based policy making and proper resource management actions.

Different fish indicators reflect the different components of fish assemblages impacted by dams. The consistent positive relationships among fish IBI and distance-to-dam measures (length of dam-free river segments, distances to an upstream dam and distances to a downstream dam) and the negative relationships among IBI and downstream dam density and abundance are clear indications that dams have negative impacts on overall river fish biotic integrity. However, the positive relationship of upstream dam abundance and IBI is unexpected. Possible explanations include that the reduction of sediment export downstream by upstream impoundments may have a positive influence on biotic integrity; and that stream flow regimes in downstream reaches may become more stable, which may benefit certain fish species. IBI is a widely used measure of the quality of the fish assemblage, and an effective method to assess the overall condition or 'health' of river ecosystems (Fausch et al., 1990). Although fish IBI has not been reported for assessing the cumulative effects of dams at a regional scale, it has been found that IBI scores were substantially improved 5 years following the removal of a dam in
Wisconsin at a local scale (Kanehl et al., 1997). Similarly, Santucci et al. (2005) also reported that river fish IBI scores were higher for free-flowing sites downstream of dams than for upstream sites in dam impounded areas for rivers in northern Illinois, just south of the Wisconsin border. These localized studies support that IBI is a suitable indicator for evaluating dam impacts at a regional scale.

Negative relationships between distance-to-dam measures and species richness and diversity emphasize that impacts of dams on river fishes are more complex than just blocking fish migratory pathways and underscore the limitations of using species richness and diversity as surrogates for measuring river health. Greater richness and diversity with decreasing proximity to dams may stem from additions of fishes tolerant of lentic conditions. Dam building converts a free-flowing section of a river into a lentic habitat that favours impoundment-dwelling fishes that free-flowing sections may have failed to support naturally. Hence, river sections far from dams in both upstream and downstream directions may have lower richness and diversity as a result. The similar patterns in relationships among distance-to-dam measures and abundances of headwater and all fishes support such an explanation. Reid et al. (2008) reported that redhorse species richness was positively correlated to river fragment size in their Pearson correlation analysis, which appears inconsistent with our results. However, the redhorse species they evaluated are fluvial species. Hence, their conclusion that longer dam-free river segments support richer riverine fish species is consistent with our findings. The negative influences of downstream dam density and upstream dam abundance on species richness and diversity may reflect the cumulative impacts of dams in both upstream and downstream directions. Cumming (2004) reported that fish species richness in Wisconsin streams had a weak negative relationship with total number of downstream dams using a path analysis model. Although our study included only dams on downstream mainstems and all sizes of rivers and Cumming (2004) included all downstream dams and only first order streams, the conclusions are consistent for these two studies.

We evaluated network effects of dams on fish assemblages at a regional scale using length of river segments free of dams to measure fragmentation size, dam density and abundance for river mainstems to measure downstream impacts and dam density and abundance for river networks to measure upstream impacts. Many of these relationships among network dam measures and fish indicators have not been evaluated in published literature. Because fish assemblages are not only affected by dams, but are also influenced by natural variations in thermal and flow regimes, physicochemical habitats, biological structures and other human-induced factors, it is extremely challenging to pinpoint the actual causes for some of the dam-fish association 
without having a controlled study condition. We attempted to minimize the influences of land uses that may mask our ability to detect dam effects by using stream segments that have minimal urban and agricultural land uses in their catchments and to control for effects of river size by standardizing fish variables using river linkage number. Although our approaches could not completely eliminate the influences of these two and other sets of covariates such as temperature and connectivity with larger water bodies, our qualitative visual analysis of CCA plots, multivariate partition in variance of fish indicators explained by dams and other environmental variables, and the univariate covariates exclusion analysis approaches provide convincing results in that dams have strong cumulative influences on river fish assemblages.

\section{ACKNOWLEDGEMENTS}

The authors thank Troy Zorn for providing insightful discussion in standardizing fish abundance data from different sampling gears and Paul Seelbach for providing landscape view related to how fragmentation impacts riverine fishes. Matthew Mitro, Dan Sullivan and two anonymous reviewers provided in depth review, which substantially improved the manuscript. This project was partially supported by Federal Aid in Sport Fishery Restoration Program, Project F-80-R-6 through the Fisheries Division of the Michigan Department of Natural Resources and Project F-95-P through the Bureau of Science Services of the Wisconsin Department of Natural Resources, and a grant from the U.S. Fish and Wildlife Service through Michigan State University.

\section{REFERENCES}

Allan JD, Castillo MM. 2007. Stream Ecology: Structure and Function of Running Waters. 2nd edn. Springer: Dordrecht, Netherlands.

Brenden TO, Clark RD, Cooper AR, Seelbach PW, Wang L, Aichele SS, Bissell EG, Stewart JS. 2006. A GIS framework for collecting, managing, and analyzing multi-scale landscape variables across large regions for river conservation and management. American Fisheries Society Symposium 48: 49-74.

Brenden T, Wang L, Seelbach PW. 2008. A landscape-based river classification system for Michigan rivers and streams for fisheries and environmental management. Transactions of the American Fisheries Society 137: $1621-1636$

Cumming GS. 2004. The impact of low-head dams on fish species richness in Wisconsin, USA. Ecological Application 14: 1495-1506.

ESRI. 2002. PC ARC/GIS Version 8.2. Environmental System Research Institute, Redlands, California.

Fausch KD, Lyons J, Karr JR, Angermeier PL. 1990. Fish communities as indicators of environmental degradation. American Fisheries Society Symposium 8: 123-144.

Fukushima M, Kameyama S, Kaneko M, Nakao K, Steel EA. 2007. Modeling the effects of dams on freshwater fish distributions in Hokkaaido, Japan. Freshwater Biology 52: 1511-1524.
Greathouse EA, Pringle CM, McDowell WH, Holmquist JG. 2006. Indirect upstream effects of dams: consequences of migratory consumer extirpation in Puerto Rico. Ecological Applications 16: 339-352.

Helfman GS. 2007. Fish Conservation: A Guide to Understanding and Restoring Global Aquatic Biodiversity and Fishery Resources. Island Press: Washington, D.C.

International Rivers. 2009. Damming statistics. Http://internationalrivers.org/en/node/479

Kanehl PD, Lyons J, Nelson JE. 1997. Changes in the habitat and fish community of the Milwaukee River, Wisconsin, following removal of the Woolen Mills dam. North American Journal of Fisheries Management 17: $387-400$.

Lessard JL, Hayes DB. 2003. Effects of elevated water temperature on fish and macroinvertebrate communities below small dams. River Research and Applications 19: 721-732.

Lyons J. 1992. Using the index of biotic integrity (IBI) to measure environmental quality in warmwater streams of Wisconsin. U.S. Forest Service, St. Paul, Minnesota, General Technical Report NC-149.

Lyons J, Wang L, Simonson TD. 1996. Development and validation of an index of biotic integrity for cold-water streams in Wisconsin. North American Journal of Fisheries Management 16: 241-256.

Lyons J, Piette RR, Niermeyer KW. 2001. Development, validation, and application of a fish-based index of biotic integrity for Wisconsin's large warmwater rivers. Transactions of the American Fisheries Society 130: 1077-1094.

Magurran AE. 1988. Ecological Diversity and its Measurement. Princeton University Press: Princeton, New Jersey.

Poff NL. 1997. Landscape filters and species traits: towards mechanistic understanding and prediction in stream ecology. Journal of the North American Benthological Society 16: 391-409.

Pringle C. 2003. What is hydrologic connectivity and why is it ecologically important? Hydrological Processes 17: 2685-2689.

Pringle MP, Freeman MC, Freeman BJ. 2000. Regional effects of hydrologic alterations on riverine macrobiota in the new world: tropicaltemperate comparison. BioScience 50: 807-823.

Reid SM, Mandrak NE, Carl LM, Wilson CC. 2008. Influence of dams and habitat condition on the distribution of redhorse (Moxostoma) species in the Grant River watershed, Ontario. Environmental Biology of Fishes 81: $111-125$.

Rosenberg DM, Berkes F, Boadaly RA, Hecky RE, Kelly CA, Rudd JWM. 1997. Large-scale impacts of hydroelectric development. Environmental Reviews 5: 27-54.

Santucci VJ, Gephard SR, Pesciteli SM. 2005. Effects of multiple low-head dams on fish, macroinvertebrates, habitat, and water quality in the Fox River, Illinois. North American Journal of Fisheries Management 25: 975-992.

SAS. 2003. SAS/STAT user's guide. Version 9.1. SAS Institute, Cary, North Carolina.

Seelbach PW, Wiley MJ. 1997. Overview of the Michigan rivers inventory project. Michigan Department of Natural Resources, Fish Division Technical Report 97-3, Ann Arbor, Michigan.

Seelbach PW, Lockwood RN, Ryckman JR. 1994. Efficiency of sampling river fishes with rotenone. Michigan Department of Natural Resources Fisheries Research Report 2009,Ann Arbor, Michigan.

Strayer DL, Beighley RE, Thompson LC, Brooks S, Nilsson C, Pinay G, Naiman RJ. 2003. Effects of land cover on stream ecosystems: roles of empirical models and scale issues. Ecosystem 6: 407-423.

ter Braak CJF, Smilauer P. 1998. CANOCO Reference Manual and User's Guide to Canoco for Windows: Software for Canonical Community Ordination (version 4). Microcomputer Power, Ithaca, NY.

USACE (U.S., Army Corps of Engineers). 2009. National inventory of dams. Https://rsgis.crrel.usace.army.mil/apex/f?p=397:1:2138130000563724 
Wang L, Lyons J, Kanehl P, Gatti R. 1997. Influence of watershed land use on habitat quality and biotic integrity in Wisconsin streams. Fisheries 22(6): 6-12.

Wang L, Lyons J, Rasmussen P, Kanehl P, Seelbach P, Simon T, Wiley M, Baker E, Niemela S, Stewart M. 2003a. Influences of landscape- and reach-scale habitat on stream fish communities in the Northern Lakes and Forest ecoregion. Canadian Journal of Fisheries and Aquatic Science 60: 491-505.

Wang L, Lyons J, Kanehl P. 2003b. Impacts of urban land cover on trout streams in Wisconsin and Minnesota. Transactions of the American Fisheries Society 132: 825-839.
Wang L, Seelbach PW, Hughes RM. 2006. Introduction to landscape influences on stream habitats and biological assemblages. American Fisheries Society Symposium 48: 1-23.

Wang L, Brenden T, Seelbach PW, Cooper A, Allan JD, Clark R Jr, Wiley M. 2008. Landscape based identification of human disturbance gradients and references for streams in Michigan. Environmental Monitoring and Assessment 141: 1-17.

Wehrly KE, Brenden TO, Wang L. 2009. A comparison of statistical approaches for predicting stream temperatures across heterogeneous landscapes. Journal of the American Water Resources Association 45: 986-997. 